\title{
Analisis Kebutuhan dalam Pengembangan Model Pendidikan Multikultur Transsformatif dalam Pembelajaran PPKn dan IPS di Sekolah Dasar
}

\author{
I Made Sumantri ${ }^{*}$, Gede Wira Bayu ${ }^{2}$, I Made Sugiartha ${ }^{3}$ \\ ${ }^{1}$ Elementary Teacher Education Department, Faculty of Education, Universitas Pendidikan Ganesha, Indonesia \\ 2 Elementary Teacher Education Department, Faculty of Education, Universitas Pendidikan Ganesha, Indonesia \\ 3 Mathematics education Department, Faculty of Education, Universitas Pendidikan Ganesha, Indonesia
}

\begin{abstract}
Abstrak
Tujuan umum dari penelitian ini adalah: mengembangkan materi dan model pendidikan multikultur dalam pembelajaran PPKn dan IPS di SD. Penelitin ini menggun desain penelitian dan pengembangan (research and development), yang dilaksan selama 3 (tiga) tahun, mulai dari tahun 2017 - tahun 2009. Hasil penelitian menunjukkan bahwa: (1) sekolah dan guru telah memiliki kesiapan yang cukup signifikan untuk dilibatkan dalm pengembangan model pendidikan multikultur, (2) pengorganisasian materi pendidikan multikultur saat ini masih terintegrasi dengan materi PKn dan IPS, (3) penilaian yang saat ini dikembangkan oleh guru lebih mengacu pada penilaian produk atau hasil belajar dengan menggun tes tertulis bentuk uraian dan isian singkat, (4) hambatan utama guru dalam membelajarkan pendidikan multikultur adalah kurangnya pengetahuan dan keterampilan mereka tentang model-model pendidikan multikultur dan terbatasnya media pembelajaran, dan (5) model konseptual pendidikan multikultur yang dikembangkan dalam penelitian ini struktur isi materinya tidak disusun berdasarkan struktur isi disiplin ilmu, melainkan sejauh memiliki relevansi dengan struktur internal siswa yang dibangun dari hasil pengalaman-pengalaman personal dan sosiokulturalnya di dalam kehidupan masyarakat, yang mencakup: (1) konsepsi sosial, (2) konsepsi kultural, dan (3) konsepsi personal dalam balutan mata pelajaran IPS dan PKn.
\end{abstract}

Keywords:

Pendidikan multikultur transformatif

\section{Pendahuluan}

Perkembangan ilmu pengetahuan dan seni (IPTEKS) telah menghadirkan tantangan dan sekaligus peluang baru bagi umat manusia dalam segala dimensi kehidupannya. Kondisi ini semakin diperkuat oleh semakin menggejalanya warna kehidupan global, sehingga setiap manusia dan bangsa harus selalu siap untuk melakoni kehidupan global yang tanpa batas. Globalisasi merup implikasi logis dari kemajuan IPTEKS. Revolusi informasi dan komunikasi sebagai dampak langsung dari kemajuan IPTEKS telah menghilangkan batasan-batasan region dan kewilayahan, sehingga bagi masyarakat tertentu, kondisi ini harus disikapi dengan cepat dan komprehensif sehingga mereka tidak kehilangan jati diri bangsa dan negaranya. Bagi bangsa Indonesia, kondisi tersebut tentu merup realitas yang harus disikapi secara seksama dan sesegera mungkin, mengingat karakteristik geografis dan sosial-budaya yang sangat beragam. Keberagaman suku, agama, etnis, dan bahasa telah menjadi warna abadi bangsa Indonesia. Oleh sebab itu, pemahaman terhadap keragaman oleh setiap masyarakat merup sebuah kewajiban. Negara multikultural seperti Indonesia harus antisipatif dan responsif terhadap fenomena heterogenitas kebudayaan dengan sikap arif dan bijak. Perbedaan yang selama ada disatu sisi telah menimbulkan dampak negatif berupa konflik yang melanda negeri ini, yang salah satunya disebabkan heterogenitas atau deferensiasi sosial dari masyarakat. Keberadaan mata pelajaran PPKn juga belum cukup untuk menanamkan kesadaran multikulturalisme. Bahkan, pendidikan IPS yang selama ini ditanamkan pada anak didik masih banyak mengandung unsur yang menghambat kesadaran multikultural. Hal ini seperti yang disampaikan Asyar'i (Kompas, 3 September 2004) bahwa: pada sisi yang lain, kita pun meras bahwa pendidikan IPS yang diberikan di sekolah pada umumnya tidak menghidupkan pendidikan multikultural yang baik, bahkan cenderung kontraproduktif. Terkait dengan hal di atas, bila kita merefleksi dan memprediksi tantangan kehidupan global dan pentingnya menjaga stabilitas serta integritas bangsa, maka ada sejumlah strategi pendidikan yang harus dikembangkan seperti: peningkatan pendidikan moral dan

\footnotetext{
* Corresponding author.

E-mail Addresses imadesumantri.@undiksha.ac.id (I Made Sumantri)
} 
budi pekerti, penanaman pemahaman dan kesadaran (literasi) terhadap keberagaman kultur kebangsaan, perbaikan kualitas proses dan produk pembelajaran, penyiapan perangkat instruksional yang mendukung peningkatan mutu pendidikan, dan hal-hal lain yang bersifat mikro seperti pengembangan model dan strategi pembelajaran yang visibel bagi pembelajara multikultur. Berdasarkan rasional di atas, maka penelitian ini diarahkan pada upaya pengembangan model dan perangkat pendidikan multikultur, sehingga produk dari penelitian ini dapat digun oleh para guru dalam melaksan pendidikan multikultur yang terintegrasi secara holistik dalam satuan mata pelajaran. Secara rinci masalah penelitian pada tahun pertama ini dapat diformulasikan sebagai berikut: (1) bagaimanakah kesiapan sekolah dan guru SD di Provinsi Bali dalam melaksan pendidikan multikultur ?, (2) bagaimanakah pengorganisasian materi pendidikan multikultur yang selama ii telah dilaksan oleh guru dalam pembelajaran PPKn dan IPS SD di Provinsi Bali ?, (3) bagaimanakah kondisi aktual penilaian pendidikan multikultur di SD dalam pembelajaran PPKn dan IPS di Provinsi Bali ?, (4) hambatan-hambatan apa yang dialami oleh para guru PPKn dan IPS SD dalam pengorganisasian materi dan penilaian hasil belajar siswa ?, dan (5) bagaimana model konseptual pendidikan multikultur yang dikembangkan dalam pembelajaran PKn dan IPS SD?

Pada tahun pertama, fokus penelitian adalah studi analisis kebutuhan (need assesment) melalui studi empirik bertalian dengan: (1) model pengorganisasian materi ajar yang selama ini dilakukan oleh guru, (2) model dan proses pembelajaran yang dikembangkan oleh guru, (3) model dan proses penilaian hasil belajar PPKn dan IPS yang dilakukan oleh guru, (4) hambatan yang dialami oleh guru dalam melaksan pendidikan multikultur, dan (5) model awal prototyfe konseptual pendidikan multikultur dalam PKn dan IPS.

Indonesia adalah negara multikultural dengan keanekaragaman agama, adat istiadat, budaya, dan suku bangsa. Keanekaragaman tersebut merup kekayaan dan aset yang sangat berharga. Namun, masih terdapat dampak negatif akibat dari keanekaragaman tersebut. Sebagai contoh adalah masih timbul konflik, baik antar agama maupun suku bangsa. Kasus yang menonjol adalah konflik antar etnis Madura dan Dayak di Kalimantan. Perbedaan agama menjadi salah satu pemicu terjadinya konflik di Ambon dan Sulawesi. Kedua konflik tersebut merup sebagian dari kasus bagaimana suatu perbedaan menimbulkan dampak negatif. Seharusnya keberagaman yang ada dalam tubuh bangsa Indonesia, menjadi kekuatan yang tangguh apabila diolah secara baik dan benar. Terjadinya konflik, baik antar etnis di Kalimantan maupun antar agama di Ambon dan Sulawesi bukan disebabkan semata oleh benturan alamiah masyarakat di tingkat lokal. Dimensi politik, ekonomi, dan kebij pemerintah memiliki peran tersendiri. Ketidakadilan akibat distribus yang tidak merata, kebij pemerintah dalam segala bidang yang cenderung trickle down sangat rentan menjadi pemicu munculnya konflik horizontal.

Bagaimana mengatasi problematika negatif dalam keberagaman bangsa Indonesia? Sebagai salah satu media adalah pendidikan yang sangat besar peranannya dalam membentuk karakter bangsa. Salah satu bagian penting pendidikan untuk menanamkan konsep keberagaman adalah Pendidikan IPS. Pendidikan IPS sangat besar pengaruhnya dalam membentuk kesadaran dan karakter bangsa. Secara substansial, IPS dapat mengembangkan kesadaran multikultural yang bersifat normatif. Apakah implementasi pendidikan yang dilaksan selama ini telah mencapai taraf normatif ? atau sekedar pendidikan multikultural deskriptif, yang hanya memberikan penjelasan bagaimana bangsa Indonesia dengan Bhinneka Tungga Ika layaknya mutiara di katulistiwa ?. Pertanyaan tersebut harus mendapat jawaban dari berbagai fihak melalui serangkaian upaya terprogram dan bertujuan, sehingga apa yang menjadi misi pendidikan nasional benar-benar diterjadikan secara nyata.

Pendidikan multikultur merup konsep pendidikan yang muncul pada masa setelah Perang Dunia II. Pendidikan multikultur merup gejala baru di dalam pergaulan umat manusia yang mendamb persamaan hak, termasuk hak untuk mendapatkan pendidikan. Pendidikan multikultur menjadi acuan beberapa negara, baik di Amerika, Eropa, Asia, dan Australia yang penduduknya relatif heterogen. Frazier dan Garcia seperti yang dikutip Tilaar (2004:122), menyat bahwa yang dimaksud dengan pendidikan multikultur adalah: ".. is a concept frame work, a way of thinking, a philosophycal view point, a value orientation, and a set of criteria for making decission that better genie the educational needs of culturally diverse student populations". Appiah (1994) menyat bahwa pendidikan multikultur menekankan pada kesederajatan dalam memperoleh kesempatan pendidikan kepada seluruh masyarakat yang memasukkan seluruh partisipasi siswa dalam berbagai hal, seperti yang ia ungkapkan sebagai berikut: "we may define multicultural education as a field study designed to increase educational equity for all students that incorporates, for this purpose, content, concepts, principles, theories, and paradigms from history, the social and behavioral sciences, and particulary from ethnic studies and women studies".

Sementara Asyari'e, (2004) menyat bahwa yang dimaksud dengan pendidikan multikultur adalah proses penanaman cara hidup menghormati, tulus, dan toleran terhadap keanekaragaman budaya yang hidup di tengah-tengah masyarakat plural. Melalui pendidikan multikultur, diharapkan adanya kekenyalan dan kelenturan mental bangsa menghadapi benturan konflik sosial, sehingga kesatuan dan persatuan 
bangsa tidak mudah patah dan retak. Oliver (1991) menyat bahwa: "multicultural education nonetheless represents a change in educational thinking, because that is can help individuals and communities value and preserve their own cultural uniqueness, so can serve the same function more generally".

Secara tipologis, menurut Banks (1995) terdapat lima model pendidikan multikultur yang berkembang, yaitu: (1) mengajar kelompok siswa yang memiliki budaya yang lain (cultural difference), (2) hubungan manusia (human relation), membantu siswa dalam melakukan percampuran antar kelompok, (3) single group studies, yakni program yang mengajarkan hal-hal yang memajukan pluralisme tetapi tidak menekankan adanya stratifikasi sosial dalam masyarakat, (4) pendidikan multikultur melalui reformasi pendidikan yang menyedi kurikulum serta materi pelajaran yang menekankan kepada adanya perbedaan siswa dalam bahasa, yang keseluruhannya untuk memajukan pluralisme kebudayaan dan equalitas sosial, (5) pendidikan multikultural yang sifatnya rekonstruksi sosial, dengan tujuan menyatukan keberagaman dan menantang ketimpangan sosial yang ada dalam masyarakat. Bagaimana membangun konsep pendidikan multikultur untuk Indonesia ?. Tentu pertanyaan tersebut bukan persoalan mudah untuk dicari jawabannya. Namun menyadari bahwa tantangan globalisasi dan revolusi telekomunikasi yang semakin menggejala, maka konsep dan model pendidikan multikultur untuk Indonesia harus dikembangkan.

\section{METODE PENELITIAN}

Penelitian ini adalah penelitian pengembangan yang mengacu pada model pengembangan Gall, Gall dan Borg (2003). Dalam penelitian ini tahap pengembangan yang dilaporkan adalah pada tahapan Analisis Kebutuhan (Need Assesment) melalui Studi Empirik, Penelitian ini melibatkan 38 Sekolah Dasar yang tersebar di wilayah perkotaan, pinggiran, dan pedesaan. Pada tahapan ini data dikumpulkan dengan metode observasi, dokumentasi, dan wawancara. Data yang dikumpulkan adalah pokok-pokok materi pendidikan kultikultur, rencana pembelajaran, pengorganisasian materi, model pembelajaran, perangkat dan proses penilaian, pelaporan penilaian, sumber pembelajaran, beban kerja guru, ketersediaan fasilitas, pengalaman pre-service training, dukungan kepala sekolah, dan lingkungan belajar. Data yang dikumpulkan dianalisis dengan tehnik analisis deskriptif kauntitatif dan deskriptif kualitatif.

\section{HASIL DAN PEMBAHASAN}

Secara administratif-pedagogis, sekolah dan guru SD di Provinsi Bali telah memiliki kesiapan yang signifikan dalam pengembangan pendidikan multikultur yang diintegrasikan dalam pembelajaran IPS dan PKn. Secara personal, kesiapan ini dinyat melalui respon yang sangat positif ketika peneliti mewawancarai mereka dan melakukan observasi langsung ketika dilakukan pembelajaran IPS dan PKn di masing-masing sekolah sampel. Sementara secara kelembagaan, kepala sekolah dengan sangat terbuka menyat kesiapannya untuk mendukung dan membantu pelaksanaan pengembangan pendidikan multikultur di sekolah yang dipimpinnya. Kedua indikator tersebut dapat dijadikan sebagai dasar tentang kesiapan sekolah dan guru dalam mengembangkan model pendidikan multikultur yang menjadi fokus dalam penelitian ini.

Secara paradigmatik pengorganisasian materi pendidikan multikultur dalam pembelajaran IPS dan PKn yang saat ini dilakukan oleh guru lebih disandarkan pada program pendidikan terintegrasi yang bersifat pedagogis, sosiokultural, dan psikologis, yang bertujuan memfasilitasi siswa mengembangkan kompetensi-kompetensi dasar personal, sosial dan intelektualnya yang dibutuhkan untuk mengkonstruksi dan me-rekonstruksi keberagaman dan keberbedaa diri dan lingkungannya secara berkesinambungan dalam struktur pengetahuan, nilai, sikap, dan tind nya dalam berbagai latar kehidupan pribadi, sosial dan kultural. Sementara materi pendidikan multikultur belum berdiri sendiri sebagai sebuah topik mandiri, melankan terintegrasi secara holistik dalam sebaran materi pembelajaran PKn dan IPS. Sementara kompetensi-kompetensi pendidikan multikultur yang dikembangkan oleh guru selama ini bertalian dengan: kesadaran, kebersamaan, toleransi, demokrasi, kebudayaan, dan idiologi.

Model penilaian materi pendidikan multikultur yang selama ini dkembangkan oleh guru dalam pembelajaran PKn dan Ips lebih banyak bersandar pada penilaian produk dengan menggun instrumen penilaian berupa tes hasil belajar bentuk uraian dan menjawab singkat. Pola dan instrumen penilaian yang dominan menggun tes tertulis dan hanya dilakukan pada akhir pembelajaran, kurang relevan dengan karakteristik pendidikan multikultur yang lebih menekankan pada keterampilan proses dan sikap yang dinamis selama berlangsungnya pembelajaran. Realitas ini merup peluang terbuka dan sangat 
memungkinkan untuk mengembangkan model penilaian yang lebih komprehensif dan membumi dalam pendidikan multikultur yang terintegrasikan dalam pembelajaran PKn dan IPS pada tahun kedua penelitian ini.

Hambatan mendasar yang saat ini dialami oleh guru dalam membelajarkan materi pendidikan multikultur delalui pembelajaran PKn dan IPS adalah: (1) terbatasnya kemampuan dan keterampilan instruksional guru itu sendiri, (2) terbatasnya sarana dan prasarana pembelajaran yang dapat dijadikan sebagai media pembelajaran multikultur, (3) jumlah kelas yang relatif gemuk dengan siswa di atas 45 orang sangat menyulitkan guru dalam melakukan layanan belajar dan mengelola kelas, (4) model-model pembelajaran pendidikan multikultur yang ada di sekolah sangat terbatas, dan (5) sebaran standar kompetensi dan kompetensi dasar IPS dan PKn sangat sulit ntuk dikemas secara sparated, sehingga guru tidak bisa membelajarkan pendidikan multikultur dalam kemasan materi tersendiri.

Model konseptual pendidikan multikultur yang dikembangkan dalam penelitian tahun kedua (tahun 2008) berdasarkan analisis kebutuhan yang telah dilakukan pada dasarnya struktur isi materinya tidak disusun berdasarkan struktur isi disiplin ilmu, melainkan sejauh memiliki relevansi dengan struktur internal siswa yang dibangun dari hasil pengalaman-pengalaman personal dan sosiokulturalnya di dalam kehidupan masyarakat, yang mencakup: (1) konsepsi sosial, yang secara eklektik memuat pengetahuan "fungsional" dan "non-fungsional" tentang keberagaman lingkungannya; (2) konsepsi kultural, yang secara eklektik memuat struktur sintaksis budaya keseharian siswa dan struktur sintaksis pengalaman dirinya dalam kehidupan bermasyarakat, dan (3) konsepsi personal, yang memuat nilai-nilai, normanorma, dan sikap-sikap, yang sudah menjadi belief dirinya dan realitas masyarakatnya, dan nilai-nilai, norma-norma, dan sikap-sikap personal dan sosiokultural siswa sebagai mahluk yang pribadi dalam balutan mata pelajaran IPS dan PKn. Dengan demikian, pengembangan materi pendidikan multikultur dalam penelitian ini lebih didasarkan pada prinsip didasarkan pada prinsip "a student's psychological, sociocultural, and intellectual horizons reconstructions character-based", bukan berdasarkan pada "structure of discipline". Hal ini penting agar organisasi dan struktur materi pendidikan multikultur lebih kontekstual, relevan, dan bermakna bagi siswa, dan tidak merusak "indigenous structure" yang telah terbentuk dan berkembang pada diri siswa.

Berlandaskan pada temuan penelitian di atas, pendidikan multikultur dalam pembelajaran PKn dan IPS dalam penelitian ini dilakukan secara integratif dan holistik. Hal ini didasari oleh rasional bahwa esensi dari pembelajaran PPKn adalah bagaimana menjadikan siswa sebagai warga negara yang paham dan sadar (literasi) hak dan kewajibannya sebagai warga masyarakat, bangsa, dan negara yang terikat oleh berbagai piranti hukum formal dan adat istiadat. Melalui PKn siswa dapat belajar dan melatihkan potensi dirinya secara optimal tentang tata cara hidup, menghadapi masalah, dan menyelesaikan masalah berdasarkan peraturan formal yang berlaku, sehingga terwujudnya stabilitas nasional yang kondusif. Upaya pembangunan stabilitas nasional yang kondusif harus dilandasi oleh pemahaman yang memadai terhadap keberagaman suku bangsa dan adat istiadat yang dimiliki oleh bangsa Indonesia.

\section{REKOMENDASI}

Secara administratif-pedagogis, sekolah dan guru SD di Provinsi Bali telah memiliki kesiapan yang signifikan dalam pengembangan pendidikan multikultur yang diintegrasikan dalam pembelajaran IPS dan PKn. Secara personal, kesiapan ini dinyat melalui respon yang sangat positif ketika peneliti mewawancarai mereka dan melakukan observasi langsung ketika dilakukan pembelajaran IPS dan PKn di masing-masing sekolah sampel. Sementara secara kelembagaan, kepala sekolah dengan sangat terbuka menyat kesiapannya untuk mendukung dan membantu pelaksanaan pengembangan pendidikan multikultur di sekolah yang dipimpinnya. Kedua indikator tersebut dapat dijadikan sebagai dasar tentang kesiapan sekolah dan guru dalam mengembangkan model pendidikan multikultur yang menjadi fokus dalam penelitian ini.

Model konseptual pendidikan multikultur yang dikembangkan dalam penelitian tahun kedua (tahun 2008) berdasarkan analisis kebutuhan yang telah dilakukan pada dasarnya struktur isi materinya tidak disusun berdasarkan struktur isi disiplin ilmu, melainkan sejauh memiliki relevansi dengan struktur internal siswa yang dibangun dari hasil pengalaman-pengalaman personal dan sosiokulturalnya di dalam kehidupan masyarakat, yang mencakup: (1) konsepsi sosial, yang secara eklektik memuat pengetahuan "fungsional" dan "non-fungsional" tentang keberagaman lingkungannya; (2) konsepsi kultural, yang secara eklektik memuat struktur sintaksis budaya keseharian siswa dan struktur sintaksis pengalaman dirinya dalam kehidupan bermasyarakat, dan (3) konsepsi personal, yang memuat nilai-nilai, normanorma, dan sikap-sikap, yang sudah menjadi belief dirinya dan realitas masyarakatnya, dan nilai-nilai, norma-norma, dan sikap-sikap personal dan sosiokultural siswa sebagai mahluk yang pribadi dalam 
balutan mata pelajaran IPS dan PKn. Dengan demikian, pengembangan materi pendidikan multikultur dalam penelitian ini lebih didasarkan pada prinsip didasarkan pada prinsip "a student's psychological, sociocultural, and intellectual horizons reconstructions character-based", bukan berdasarkan pada "structure of discipline". Hal ini penting agar organisasi dan struktur materi pendidikan multikultur lebih kontekstual, relevan, dan bermakna bagi siswa, dan tidak merusak "indigenous structure".

Bertolak dari kesimpulan penelitian di atas, dapat diajukan saran-saran sebagai berikut: (1) komunitas pakar dan pengembang pembelajaran IPS dan PKn yang bergabung di lingkungan perguruan tinggi, lembaga-lembaga keilmuan, maupun forum-forum komunikasi pakar perlu lebih memantapkan rekonstruksi kompetensi dasar pendidikan multikultur, melalui kajian kritis-reflektif terhadap filsafat keberagaman bangsa dengan berfokus pada: (1) ontologi siswa sebagai subyek pendidikan yang aktif dalam proses pembentukan karakter dirinya, dan (2) hakikat keberagaman sebagai wahana pembentuk jatidiri siswa sebagai makhluk pribadi, sosial, dan intelektual yang demokratis, dan (2) komunitas pakar dan pengembang pendidikan perlu lebih jauh mengungkap karakter-karakter siswa sebagai makhluk personal, sosial, dan intelektual sebagai rujukan utama di dalam merumuskan dan mengembangkan kompetensi-kompetensi pendidikan multikultur, melalui kajian fenomenologis yang lebih intensif dan mendalam dari berbagai konteks sosio-kultural yang berbeda di Indonesia, sehingga diperoleh rumusanrumusan kompetensi dasar yang lebih kaya dan kontekstual.

\section{References}

Appiah, K. A. (1994). Identity, Authenticity, Survival: Multicultural Societies and Social Reproduction. Dalam Amy Gutmann (Ed), Multiculturalism. Princeton, Ney Jersey: Princeton University Press.

Asyar'i, L. (2004). Membebaskan Diri dari Keterikatan Lokal. Kompas, Tanggal 3 September 2004.

Banks, J. and Banks. (1995). Teaching strategies for ethnic studies. Boston: Allyn and Bacon.

Banks, J. (1995). Multicultural Education. available at. www.multiculturalism.com. Akses 21/08/2006

Bunyamin, S. (2004). Kesiapan guru PPKn mengembangkan pendidikan nilai-nilai kejuangan. (Disertasi). Bandung: PPS UPI

Boyer, E. L. (2000). Civic education for responsible citizen. Educational Leadership, 48-Nov, 4-9.

Dodd, C. H. (1998). Dynamics of Intercultural Communication (Tifth Edition). New York: McGraw-Hill.

Educational for Democracy Project. (2002). Education for democracy. American Federation of Teachers, 313 (5), 57-62.

Fadjar, A. M. (2004). Holistika Pemikiran Pendidikan. Jakarta: Radja Grafindo Persada.

Hasan, S.H. (2005). Pembaharuan Pendidikan IPS di Era Otonomi Pendidikan. (Makalah). Disajikan dalam seminar sehari Fakultas PIPS IKIP Negeri Singaraja. Singaraja: FPIPS IKIP Negeri Singaraja.

Heller, C. \& Hawkins, J. (1994). Teaching tolerance: Notes from the front line. Teachers College Record, Number 95. page 337-368.

Hidayat, Eddy M. (1997). Pendidikan Sains untuk Kelompok Multi Etnis. Mimbar Pendidikan (1) Tahun XVI 1997.

Jandt, F.E. (1998). Intercultural Communication, An Introduction (Second Edition). Thousand Oaks, California: SAGE Publication, Inc.

Jannes, E. W. (2001). Konflik Antar Etnis, Ujian Bagi Budaya Lokal. Kompas, 21 Maret 2001.

Katryn, R. (2000). Ketegangan Anta Etnis, Orang Bugis dan Masalah "Penjelasan". Jurnal Antropologi Indonesia, Nomor 63 Tahun XXXIV, September - Desember, 2000.

Kertih, W. (2005). Analisis Kurikulum IPS dan PPKn Sekolah Dasar. (Laporan Penelitian). Singaraja: Singaraja: Lembaga Penelitian IKIP Negeri Singaraja

Kurikulum PPKn SD 2004. (2004). Jakarta: Departemen Pendidikan Nasional, Dirjen Pendidikan Dasar dan Menengah.

Lasmawan, W. (2004). Pengembangan model pendidikan berdemokrasi dalam pembelajaran PPKn di Sekolah Dasar. (Laporan Penelitian). Singaraja: Lembaga Penelitian IKIP Negeri Singaraja

Lasmawan, W. (2005). Nasionalisme dikalangan masyarakat pedesaan (studi eksploratif pendidikan politik oleh partai politik di Kecamatan Kintamani - Bangli). (Laporan Penelitian). Singaraja: Lembaga Penelitian IKIP Negeri Singaraja 
Mahfud, A. (2004). Model pengorganisasian materi IPS di SMU (Studi kebij dalam konteks pendidikan sekolah). (Laporan Penelitian). Palu: Lemlit UNTAD.

Maria, H. (2001). Asimilasionisme vs Multikulturalisme. Kompas, 14 Maret 2001.

McCarthy, C. (1994). Multicultural discourses and curriculum reform: A critical perspective. Educational Theory, number 44-vol.1, page 81-83.

Moultry, M. (1988). Multicultural education among seniors in the College of Education at Ohio State University. Educational Research, 45 (2). 124-126.

NCSS. (2004). Science-Technology-Society (STS) in Social Studies: Position Paper. Washington DC: NCSS.

NCSS. (2005). Guidelines for Teaching About Science/Technology/Society in Social Studies: Education for Citizenship in the 21st Century. (On line). Available at http://www.uow.edu.au/sts/ ncss/pubs/00nvt.html.

O'Sulivan, 1994) T. (Ed). (1994). Key Concept in Communication Cultutal Studies. New York: Routledge, Pub.

Pelly, U. (1999). Akar Kerusuhan Etnis di Indonesia. Jurnal Antropologi Indonesia, Tahun XXIII, Nomor 58, Januari-April, 1999.

Rahardjo, T. (2005). Menghargai Perbedaan Kultural: Mindfulness dalam Komunikasi Antar Etnis (Editor: Mu'amma Ramadhan). Yogjakarta: Pustaka Pelajar.

Schement, J. R. (2002). Encyclopedia of Cpmmunication and Information (Volume 1). New York: McMilland Reference.

Sharon Lee. (1994). Social Studies in a Global Society. America, Canada: Delmar Publishing Inc.

Shaver, J. P. (1991). Handbook of research on social studies teaching and learning. New York, NY: McMilland Publishing Company.

Somantri, N. (2004). Menggagas pembaharuan pendidikan IPS. Bandung: Rosdakarya.

Sumantri, E. (2001). Desentralisasi Pendidikan dan Wacana Demokrasi dalam Konteks Pendidikan Nasional (Makalah). Disajikan pada Seminar Sehari Lembaga Penelitian UPI Bandung. Bandung: PPS UPI.

Suparlan, P. (2002). Masyarakat Majemuk dan Perawatannya. Jurnal Antropologi Indonesia, Nomor 63. Tahun XXIV, September - Desember, 2002.

Tilaar, H.A.R. (2004). Multikulturalisme Tantangan-tantangan Global Mada Depan dalam Transpormasi Pendidikan Nasional. akarta: Grassindo.

Ting-Toomey, S. (1999). Communicating Across Cultures. New York: The Guilford Prublications, Inc.

UNESCO. (1999). Education for international understanding and peace in Asia and the Fasific. Ichon \& Kyongju: Korean National Commission for UNESCO. 